\title{
Synthesis and Mesomorphic Properties of Diphenyl- and Biphenylyl-pyrimidines
}

\author{
Arthur Boller, Marco Cereghetti, and Hanspeter Scherrer \\ Central Research Units, F. Hoffmann-La Roche \& Co., Ltd., CH-4002 Basle
}

Z. Naturforsch. 33 b, 433-438 (1978); received December 22, 1977

Liquid Crystals, Diphenyl-pyrimidines, Biphenylyl-pyrimidines, Mesophases

The synthesis and mesomorphic properties of four classes of cyano-substituted diphenyland biphenylyl-pyrimidines are reported. The new compounds are colourless, chemically and photochemically stable and have wide mesomorphic ranges. The synthesis of one member of each homologous series is described in detail.

The use of 2,5-disubstituted pyrimidine rings as a structural element in liquid crystals is well known. Mono- and disubstituted diphenyl-pyrimidines have been studied mainly by Schubert et al. [1-3] and more recently various phenyl-pyrimidines have been prepared by Zaschke [4]. Only minor changes of the molecular geometry are expected when a phenyl group in a given liquid crystalline structure is replaced by a pyrimidine ring. However, we have shown in a recent publication [5] that a strong influence on the dielectric properties can be demonstrated. In cyano-alkylphenyl- and alkyl-cyanophenyl-pyrimidines the relative position of the permanent dipole moments of the pyrimidine and the cyano group is very important in determining the size of the dielectric constants. A large positive dielectric anisotropy [5] is obtained if the contributions are additive (see 2). On the other hand, much smaller dielectric anisotropies [5] due to the subtractive effect are observed when the two dipole moments have opposite directions (see 1).

1

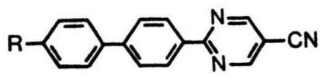

2

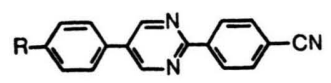

3

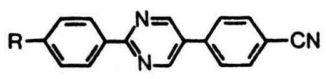

4

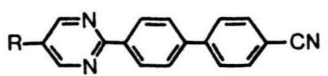

In view of the fact that there is still great interest in liquid crystalline materials with a positive anisotropy of the dielectric constants, we decided to prepare four homologous series of diphenyl- and

Requests for reprints should be sent to Dr. A. Boller, Central Research Units, F. Hoffmann-La Roche \& Co., Ltd., $\mathrm{CH}$-4002 Basle. biphenylyl-pyrimidines. Their synthesis is outlined in Schemes 1-4. 4-Substituted benzamidine hydrochlorides have been used as the nitrogen containing units for the construction of the pyrimidine ring. In series 1 (Scheme 1), condensation with diethyl ethoxymethylene-malonate forms a hydroxy-pyrimidine carboxylate. The hydroxy-group is removed by substitution with chlorine [6] and subsequent catalytic reduction. For the preparation of series 2-4 (Schemes 2-4), a substituted malonic dialdehyde tetraacetal is used as precursor, obtained from enolesters by treatment with ethyl orthoformate and boron trifluoride etherate [7]. After partial hydrolysis to the relatively unstable substituted ethoxyacrolein, a smooth condensation with a benzamidine in methanol or ethanol and sodium alkoxide takes place $[5,7]$. The cyano group is introduced either by substitution of bromine with cuprous cyanide or by dehydration of the amide with phosphorous oxychloride. The synthesis of one member of each homologous series is described in detail in the experimental part.

All transition temperatures which are listed in Table I have been determined by differential thermal analysis with an accuracy of at least $\pm 0.2^{\circ} \mathrm{C}$. Corresponding values usually within $1^{\circ} \mathrm{C}$ have also been observed by microscopic determination. Only for clearing points at temperatures over $250{ }^{\circ} \mathrm{C}$ were differences of several degrees sometimes found, microscopic observation always giving the higher value. In many samples differential thermal analysis gave broad, poorly defined exothermic peaks around $200{ }^{\circ} \mathrm{C}$ in the first melting process. When subsequently the sample was cooled, recrystallized and measured again, these peaks no longer appeared. Table I lists also the heats of melting, which, unless otherwise stated were always measured with recrystallized samples. The accuracy of the instrument is better than $\pm 5 \%$. 
Table I. Transition temperatures and heats of melting of diphenyl- and biphenylyl-pyrimidines.

\begin{tabular}{|c|c|c|c|c|c|}
\hline $\mathbf{R}$ & $\begin{array}{l}\text { m.p. } \\
{\left[{ }^{\circ} \mathrm{C}\right]^{\mathrm{a}}}\end{array}$ & & $\begin{array}{l}\text { Additional } \\
\text { transitions } \\
{\left[{ }^{\circ} \mathrm{C}\right]}\end{array}$ & $\begin{array}{l}\text { clp. } \\
{\left[{ }^{\circ} \mathrm{C}\right]}\end{array}$ & $\begin{array}{l}\Delta \mathrm{H}_{\mathrm{m}} \\
{[\mathrm{kcal} / \mathrm{mole}]}\end{array}$ \\
\hline \multicolumn{6}{|c|}{1} \\
\hline $\mathrm{C}_{2} \mathrm{H}_{5}$ & (72.5) & 166.5 & 241 & $290^{\mathrm{b}}$ & 3.1 \\
\hline $\mathrm{C}_{3} \mathrm{H}_{7}$ & & 140.5 & 234 & $289.5^{\mathrm{b}}$ & 4.2 \\
\hline $\mathrm{C}_{4} \mathrm{H}_{9}$ & $(99.5)$ & 126.5 & 216.5 & 274.5 & 2.6 \\
\hline $\mathrm{C}_{6} \mathrm{H}_{13}$ & $(90.5)$ & 134.5 & $\begin{array}{l}154^{\mathrm{c}}, 160.5^{\mathrm{c}}, \\
217.5\end{array}$ & 258 & 3.2 \\
\hline \multicolumn{6}{|c|}{2} \\
\hline $\mathrm{C}_{2} \mathrm{H}_{5}$ & & 182 & - & 262.5 & 5.3 \\
\hline $\mathrm{C}_{3} \mathrm{H}_{7}$ & & 153.5 & - & 259 & 5.4 \\
\hline $\mathrm{C}_{4} \mathrm{H}_{9}$ & & 93.5 & - & 244 & 4.2 \\
\hline $\mathrm{C}_{5} \mathrm{H}_{11}$ & & 125 & - & 241 & 6.3 \\
\hline $\mathrm{C}_{6} \mathrm{H}_{13}$ & (82.5) & 92 & 193.5 & 230.5 & 5.1 \\
\hline $\mathrm{C}_{7} \mathrm{H}_{15}$ & & 103.5 & 208.5 & 226.5 & 5.8 \\
\hline $\mathrm{C}_{3} \mathrm{H}_{7} \mathrm{O}$ & & 132 & - & $279.5^{\mathrm{b}}$ & 5.2 \\
\hline $\mathrm{C}_{4} \mathrm{H}_{9} \mathrm{O}$ & $(110)$ & 119 & - & 271.5 & 5.8 \\
\hline $\mathrm{C}_{5} \mathrm{H}_{11} \mathrm{O}$ & $(82)$ & $91.5^{\mathrm{d}}$ & 199 & 261 & $6.6^{\mathrm{d}}$ \\
\hline $\mathrm{C}_{6} \mathrm{H}_{13} \mathrm{O}$ & & 95 & 226 & 254.5 & 6.6 \\
\hline \multicolumn{6}{|c|}{$\mathbf{3}$} \\
\hline $\mathrm{H}$ & $(206.5)$ & 219.5 & - & - & 8.9 \\
\hline $\mathrm{C}_{2} \mathrm{H}_{5}$ & & 166 & I80.5 & 277 & 4.6 \\
\hline $\mathrm{C}_{3} \mathrm{H}_{7}$ & (69.5) & 166 & 180 & 276 & 4.8 \\
\hline $\mathrm{C}_{4} \mathrm{H}_{9}$ & (69.5) & 138 & 180 & 263 & 3.8 \\
\hline $\mathrm{C}_{5} \mathrm{H}_{11}$ & & 131.5 & 176 & 261.5 & 4.1 \\
\hline $\mathrm{C}_{6} \mathrm{H}_{13}$ & (91.5) & 121.5 & $\mathrm{I} 64$ & 247.5 & 3.8 \\
\hline $\mathrm{C}_{7} \mathrm{H}_{15}$ & $(103.5)$ & 121 & $146.5,150^{\mathrm{e}}$ & 242 & 3.9 \\
\hline \multicolumn{6}{|c|}{4} \\
\hline $\mathrm{C}_{3} \mathrm{H}_{7}$ & & 125.5 & 214 & 275.5 & 4.2 \\
\hline $\mathrm{C}_{4} \mathrm{H}_{9}$ & & 112 & 212.5 & 262 & 3.8 \\
\hline $\mathrm{C}_{5} \mathrm{H}_{11}$ & & 124 & 204.5 & 259.5 & 6.0 \\
\hline $\mathrm{C}_{6} \mathrm{H}_{13}$ & (95) & 108 & 215 & 246 & 6.0 \\
\hline $\mathrm{C}_{7} \mathrm{H}_{15}$ & (72) & $78^{g}$ & $109^{f}, 221.5$ & 241.5 & $-\mathbf{f}$ \\
\hline
\end{tabular}

a Values in parentheses refer to transitions between solid modifications. They do not appear after recrystallization.

b Sublimation and partial decomposition occur during microscopic examination.

c These transitions cannot be observed by polarizing microscopy.

d Values obtained by first heating. After recrystallization: m.p. $86^{\circ} \mathrm{C}$ and $\Delta \mathrm{H}_{\mathrm{m}} 3.8 \mathrm{kcal} / \mathrm{mole}$.

e A broad poorly defined transition between 144 and $151^{\circ} \mathrm{C}$ is observed by microscopic examination.

f After recrystallization a new, additional peak appears at $89.5^{\circ} \mathrm{C}$. No $\Delta \mathrm{H}_{\mathrm{m}}$ could be determined.

g This transition may be mistaken for the melting point; however, the low $\Delta \mathrm{H}_{\mathrm{m}}$ of $1.2 \mathrm{kcal} / \mathrm{mole} \mathrm{sug-}$ gests that it is a smectic-smectic transition.

Comparison of the clearing points of the four series shows a striking similarity for the series 3 and 4. Corresponding values for the isomers with the same length of the alkyl side chain differ with one exception by only $1{ }^{\circ} \mathrm{C}$ or less. The clearing points of series 1 are higher by an average of $12{ }^{\circ} \mathrm{C}$, those of series 2 lower by approximately $17^{\circ} \mathrm{C}$. A similar dependence of the mesomorphic properties on the relative positions of the pyrimidine nitrogens and the terminal substituents has been observed in monosubstituted diphenyl-pyrimidines [1] and in phenyl-pyrimidines [5]. - Only the lower members of the homologous serie 2 have a uniform mesomorphic range. Based on texture and low viscosity it has been identified as being nematic. No efforts have been made to determine the other phases.

The new materials described in this paper have high clearing points. Combined with an often relatively low melting point, some of the compounds have mesomorphic ranges as large as $150^{\circ} \mathrm{C}$ and compare favourably with $4^{\prime \prime}$-alkyl-4-cyano- $p$-terphenyls found by Gray et al. [8]. They will be valuable components for mixtures with high clearing points and a positive anisotropy of the dielectric constants.

\section{Experimental}

All compounds were recrystallized to constant melting point and identified by their mass, NMR and infrared spectra. Elemental analysis for $\mathrm{C}, \mathrm{H}$ and $\mathrm{N}$ always gave satisfactory values. Transition temperatures and heats of melting were measured with a Mettler TA 2000 thermoanalyzer system which was also used for the determination of the purity by the cryoscopic method. It was found that all compounds listed in Table I were more than $99 \%$ pure. For the microscopic determination of the transition temperatures in polarized light, a Mettler hot stage FP 52 and a Mettler FP 5 electronic recording apparatus was used. Mass spectra were recorded on a MS 9 (AEI, Manchester) spectrometer (ionizing voltage: $70 \mathrm{~V}$; ion source temperature: approx. $250^{\circ} \mathrm{C}$ ). For NMR spectra, a Varian EM 360 spectrometer $\left(\mathrm{CDCl}_{3}, \mathrm{TMS}\right)$ was used.

\section{5-Cyano-2-(4'-n-hexyl-4-biphenylyl)-pyrimidine}

(1, R= $\mathrm{C}_{6} \mathrm{H}_{13}$, Scheme 1)

Dry hydrogen chloride is passed into a solution of $5.0 \mathrm{~g}$ of $4^{\prime}-n$-hexyl-4-cyanobiphenyl [9] in $3.8 \mathrm{ml}$ of absolute ethanol and $4.8 \mathrm{ml}$ of absolute benzene for 8 hours while stirring and cooling to $0{ }^{\circ} \mathrm{C}$ and the mixture is left to stand overnight at room temperature. After evaporation in vacuo, the mixture is treated with $100 \mathrm{ml}$ of absolute ether and $4^{\prime}$ - $n$-hexyl-4-biphenyl-imidoethyl ether hydrochloride is isolated by filtration. This crude salt is suspended in $7.6 \mathrm{ml}$ of absolute ethanol and stirred for $40 \mathrm{~h}$ with $10.7 \mathrm{~g}$ of a $16 \%(\mathrm{~g} / \mathrm{g})$ solution of ammonia in ethanol. The clear solution is evaporated in vacuo and the residue is treated with $100 \mathrm{ml}$ of absolute ether. 4'-n-Hexyl-4-biphenyl-amidine hydrochloride is isolated by filtration. A mixture of 


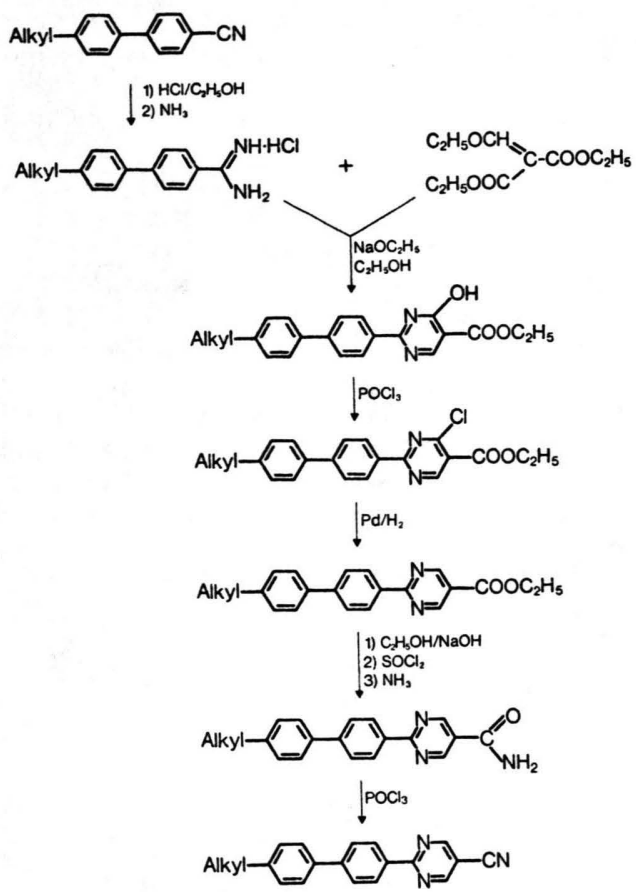

Scheme 1. Synthesis of

5-cyano-2-(4'-alkyl-4-biphenylyl)-pyrimidines.

$6.0 \mathrm{~g}$ of $4^{\prime}-n$-hexyl-4-biphenyl-amidine hydrochloride and $4.9 \mathrm{~g}$ of diethyl ethoxymethylene-malonate $[10]$ is stirred in a sodium ethylate solution (obtained from $0.867 \mathrm{~g}$ of sodium and $80 \mathrm{ml}$ of ethanol) for $40 \mathrm{~min}$ at room temperature and for $40 \mathrm{~min}$ under reflux. The yellow mixture is then evaporated in vacuo and the residue suspended in $95 \mathrm{ml}$ of water and acidified with $15 \mathrm{ml}$ of glacial acetic acid. Filtration, washing with water and drying yields crude ethyl 2-(4'-n-hexyl-4-biphenylyl)-4-hydroxypyrimidine-5-carboxylate which can be purified by sublimation at $185^{\circ} \mathrm{C}$ in a high vacuum; m.p. $218.0^{\circ} \mathrm{C}$.

$6.95 \mathrm{~g}$ of this hydroxypyrimidine are boiled for $1 \mathrm{~h}$ under reflux with $50 \mathrm{ml}$ of phosphorus oxychloride. The excess reagent is evaporated off in vacuo and the residue is chromatographed in methylene chloride on silica gel 60 . Elution with methylene chloride and methylene chloride $/ 2 \%$ acetone yields ethyl $2-\left(4^{\prime}-n\right.$-hexyl-4-biphenylyl $)-4$ chloro-pyrimidine-5-carboxylate which can be purified by distillation at $180^{\circ} \mathrm{C}$ in a high vacuum; m.p. 91.6-91.9 ${ }^{\circ} \mathrm{C}$; clp. 112.6-112.7 ${ }^{\circ} \mathrm{C}$.

$6.2 \mathrm{~g}$ of chloropyrimidine are suspended in $300 \mathrm{ml}$ of ethanol and hydrogenated in the presence of $0.4 \mathrm{~g}$ of $5 \%$ palladium-on-charcoal and $2.17 \mathrm{~g}$ of anhydrous potassium acetate at room temperature until 1 mole of hydrogen has been absorbed. The catalyst is separated and rinsed with methylene chloride and the evaporation residue is dissolved in benzene, diluted with an equivalent amount of hexane and chromatographed on silica gel 60 . Elution with hexane/benzene $(1: 1)$ and benzene initially yields a small amount of starting material and then ethyl 2-(4'-n-hexyl-4-biphenylyl)-pyrimidine-5-carboxylate. This carboxylate can be purified by distillation at $180^{\circ} \mathrm{C}$ in a high vacuum; m.p. $129.2{ }^{\circ} \mathrm{C}$; clp. $181{ }^{\circ} \mathrm{C}$.

$5.12 \mathrm{~g}$ of ethyl 2-(4'-n-hexyl-4-biphenylyl)-pyrimidine-5-carboxylate are boiled under reflux for $3 \mathrm{~h}$ with $150 \mathrm{ml}$ ethanol and $6.1 \mathrm{~g}$ sodium hydroxide in $45 \mathrm{ml}$ of water and the mixture is evaporated in vacuo. $50 \mathrm{ml}$ of water and $100 \mathrm{ml}$ of $20 \%$ hydrochloric acid are added to the residue. Filtration, washing with water and drying yields $2-\left(4^{\prime}-n\right.$-hexyl4-biphenylyl)-pyrimidine-5-carboxylic acid which can be converted into the acid chloride by boiling for $2 \mathrm{~h}$ with $30 \mathrm{ml}$ of thionyl chloride. The excess reagent is removed in vacuo and the residual acid chloride is suspended in $60 \mathrm{ml}$ of absolute dioxane and added while stirring to a solution of $80 \mathrm{ml}$ of dioxane saturated with ammonia at room temperature. Ammonia is passed into the mixture for a further $4 \mathrm{~h}$ and the mixture is left to stand overnight at room temperature. The mixture is then evaporated to dryness and the residue is stirred for $\mathbf{3 0}$ min with $100 \mathrm{ml}$ of water, filtered, rinsed with water and dried. There is thus obtained colourless $2-\left(4^{\prime}-n\right.$ hexyl - 4 - biphenylyl) - pyrimidine - 5 - carboxylic acid amide which can be purified by sublimation at $205^{\circ} \mathrm{C}$ in a high vacuum; m.p. $260^{\circ} \mathrm{C}$.

$4.31 \mathrm{~g}$ of $2-\left(4^{\prime}-n\right.$-hexyl-4-biphenylyl)-pyrimidine5 -carboxylic acid amide are boiled for $2 \mathrm{~h}$ under reflux with $75 \mathrm{ml}$ of phosphorus oxychloride and the excess reagent is removed in vacuo. Toluene is then added and the mixture is concentrated twice in vacuo. The residue is taken up in methylene chloride and chromatographed on silica gel 60 . Elution with methylene chloride $/ 2 \%$ acetone yields 5-cyano-2-(4'-n-hexyl-4-biphenylyl)-pyrimidine which is purified by recrystallization from acetone/ hexane and distillation at $180^{\circ} \mathrm{C}$ in a high vacuum; m.p. $134.5^{\circ} \mathrm{C}$; clp. $258^{\circ} \mathrm{C}$.

NMR $\delta 0.7,1.95 \mathrm{ppm}(11, \mathrm{~m}), 2.67(2, \mathrm{t}, J=7 \mathrm{~Hz})$, $7.23,7.55$ (4, centers of $\mathrm{AA}^{\prime} \mathrm{BB}^{\prime}$-spectrum), 7.68, 8.33 (4, centers of $\mathrm{AA}^{\prime} \mathrm{BB}^{\prime}$-spectrum), $8.93(2, \mathrm{~s})$; mass spectrum $m / e(\%) 341$ (M, 49), 270(100), 165(7), no other peak larger than $5 \%$.

$\mathrm{C}_{23} \mathrm{H}_{23} \mathrm{~N}_{3}$

$$
\text { Calcd } \quad \text { C } 80.91 \quad \text { H } 6.79 \quad \text { N } 12.31 \text {, }
$$

Found C 80.79 H 6.80 N 12.18 .

\section{5-(4-n-Pentylphenyl)-2-(4-cyanophenyl)-pyrimidine} $\left(2, \mathrm{R}=\mathrm{C}_{5} \mathrm{H}_{11}\right.$, Scheme 2$)$

Dry hydrogen chloride is passed into a solution of $88.6 \mathrm{~g}$ of methyl 4-cyanobenzoate in $190 \mathrm{ml}$ of benzene and $170 \mathrm{ml}$ of methanol for $3 \mathrm{~h}$ at $0{ }^{\circ} \mathrm{C}$ while stirring. The mixture is left to stand for 5 days at $+5{ }^{\circ} \mathrm{C}$ and the precipitated imido ether hydrochloride is then filtered off. $178 \mathrm{~g}$ of the crude product are suspended in $300 \mathrm{ml}$ of methanol and 


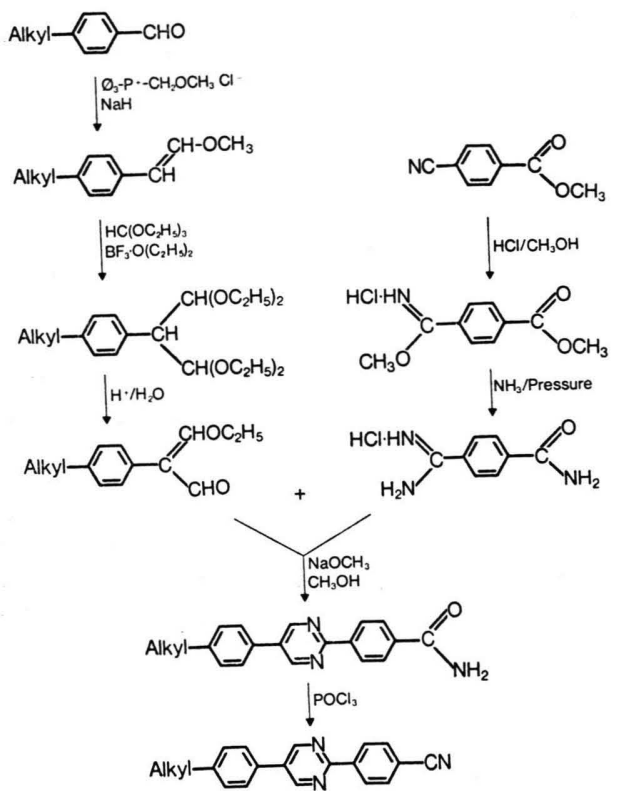

Scheme 2. Synthesis of 5-(4-alkylphenyl)-2-(4-cyanophenyl)-pyrimidines.

after cooling to about $-40^{\circ} \mathrm{C}$, treated with $130 \mathrm{~g}$ of liquid ammonia and the mixture is shaken in an autoclave for $24 \mathrm{~h}$ at $+70^{\circ} \mathrm{C}$. After cooling the mixture to room temperature and evaporation of the ammonia, the crystallized product is filtered off and the crystals are washed with hexane and dried overnight at $50^{\circ} \mathrm{C}$ under a waterpump vacuum, there being obtained 4-amidino-benzoic acide amide hydrochloride.

$46.07 \mathrm{~g}$ of 1-(4- $n$-pentylphenyl)-2-methoxyethylene [11] are added dropwise to a solution of $2 \mathrm{ml}$ of boron trifluoride etherate in $500 \mathrm{ml}$ of ethyl orthoformate, cooled in an ice bath, and the mixture is then further stirred at room temperature. After dilution with ether, extraction with $1 \mathrm{~N}$ sodium hydroxide solution and water and evaporation of the organic phase, which is previously dried over sodium sulphate, there is obtained 4- $n$-pentylphenyl-malonic tetraacetal.

$7.33 \mathrm{~g}$ of $4-n$-pentylphenyl-malonic tetraacetal in $20 \mathrm{ml}$ of ethanol are stirred overnight at $50^{\circ} \mathrm{C}$ under nitrogen with $0.72 \mathrm{ml}$ of water and 2 drops of concentrated sulphuric acid. The acidic pentylphenyl-malonic aldehyde obtained as a by-product can be separated from the neutral 2-(4-n-pentylphenyl)-3-ethoxy-acrolein by extracting the mixture after dilution with ether, with aqueous sodium carbonate solution.

$4.46 \mathrm{~g}$ of this 3 -ethoxy-acrolein and $3.63 \mathrm{~g}$ of the foregoing 4-amidinobenzoic acid amide hydrochloride are stirred in a solution of $0.584 \mathrm{~g}$ of sodium metal in $250 \mathrm{ml}$ of methanol overnight at room temperature under nitrogen. The yellow suspension is then filtered and the residue is washed with a small amount of ethanol and suspended in $1.4 \mathrm{l}$ of ether for further purification. The suspension is washed with water and then filtered again. Sparingly soluble 4-[5-(4- $n$-pentylphenyl)-2-pyrimidinyl]-benzoic acid amide is obtained.

$4.2 \mathrm{~g}$ of 4 -[5-(4- $n$-pentylphenyl)-2-pyrimidinyl]benzoic acid amide are left under reflux for $1 \mathrm{~h}$ while stirring in a mixture of $200 \mathrm{ml}$ of ethylene chloride and $2.5 \mathrm{ml}$ of phosphorus oxychloride. The mixture is diluted with ether and washed with $2 \mathrm{~N}$ sodium hydroxide solution and then with water until neutral. After drying the organic phase over sodium sulphate and evaporation, there is obtained 5-(4-n-pentylphenyl)-2-(4-cyanophenyl)-pyrimidine which is filtered through a short silica gel column and subsequently recrystallized from methylene chloride/methanol; m.p. $125^{\circ} \mathrm{C}$; clp. $241^{\circ} \mathrm{C}$.

NMR $\delta 0.7-2.0 \mathrm{ppm}(9, \mathrm{~m}), 2.67(2, \mathrm{t}, J=7.5 \mathrm{~Hz})$, $7.28,7.53$ (4, centers of $\mathrm{AA}^{\prime} \mathrm{BB}^{\prime}$-spectrum), 7.70, 8.57 (4, centers of $\mathrm{AA}^{\prime} \mathrm{BB}^{\prime}$-spectrum), $9.01(2, \mathrm{~s})$; mass spectrum $m / e(\%) 327(\mathrm{M}, 52), 270(100), 115(24)$, no other peak larger than $5 \%$.

$\mathrm{C}_{22} \mathrm{H}_{21} \mathrm{~N}_{3}$

Calcd C 80.70 H 6.46 N 12.83 ,

Found C 80.77 N 6.28 N 12.80.

The corresponding 5-(4- $n$-alkoxyphenyl)-2-(4cyanophenyl)-pyrimidines are prepared in an analogous manner.

\section{2-(4-n-Hexylphenyl)-5-(4-cyanophenyl)-pyrimidine (3, $\mathrm{R}=\mathrm{C}_{6} \mathrm{H}_{13}$, Scheme 3)}

$4.5 \mathrm{~g}$ of 4 -bromophenyl-malonic tetraacetal, prepared in a similar manner as described in the synthesis of compounds 2 , are dissolved in $10 \mathrm{ml}$ of ethanol. The solution is treated with $0.5 \mathrm{ml}$ of water and 1 drop of concentrated sulphuric acid and the mixture is stirred overnight at $50{ }^{\circ} \mathrm{C}$ and then worked up in the customary manner.

$2.5 \mathrm{~g}$ of this crude 2-(4-bromophenyl)-3-ethoxyacrolein in $20 \mathrm{ml}$ of methanol and then $2.4 \mathrm{~g}$ of 4- $n$-hexylbenzamidine hydrochloride [2] are added

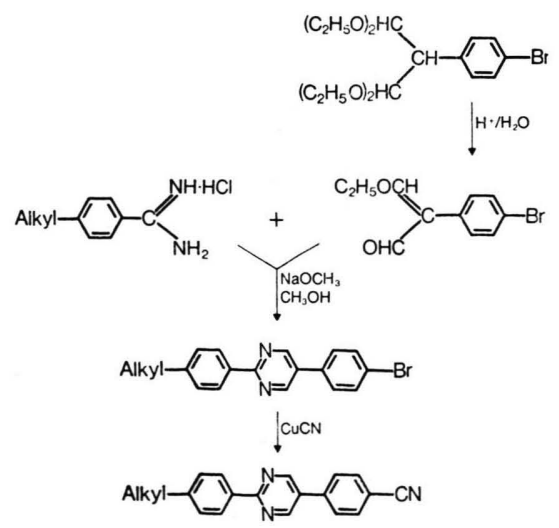

Scheme 3. Synthesis of 2-(4-hexylphenyl)-5-(4-cyanophenyl)-pyrimidines. 
to a sodium methylate solution obtained from $0.7 \mathrm{~g}$ of sodium in $25 \mathrm{ml}$ of methanol. The mixture is heated to the reflux overnight. The solvent is then partially distilled off, the residue is treated with water and subsequently acidified with dilute hydrochloric acid. The resulting precipitate is filtered off, washed thoroughly with water and ether and dried. The crude 2-(4-n-hexylphenyl)-5-(4-bromophenyl)pyrimidine of melting point $152.5-156^{\circ} \mathrm{C}$ is used in the process without further purification.

$1.9 \mathrm{~g}$ of 2 -(4-n-hexylphenyl)-5-(4-bromophenyl)pyrimidine in $50 \mathrm{ml}$ of dimethylformamide are heated to reflux for $21 \mathrm{~h}$ with $2.5 \mathrm{~g}$ of copper(I) cyanide. After cooling, the mixture is stirred with $25 \mathrm{ml}$ of $10 \%$ aqueous ethylenediamine solution and then extracted with methylene chloride. The extract is washed again with ethylenediamine solution and then several times with water until it gives a neutral reaction. The crude product obtained after evaporation is chromatographed on $150 \mathrm{~g}$ of silica gel with toluene $/ 1 \%$ acetone. Initially there are obtained traces of the starting material and then fractions containing pure 2-(4-n-hexylphenyl)-5-(4-cyanophenyl)-pyrimidine. After recrystallization from ethyl acetate, the product has a melting point of $121.5^{\circ} \mathrm{C}$ and a clearing point of $247.5^{\circ} \mathrm{C}$.

NMR $\delta$ 0.7-1.9 ppm (11, m), $2.70(2, \mathrm{t}, J=7 \mathrm{~Hz})$, 7.28, 8.35 (4, centers of $\mathrm{AA}^{\prime} \mathrm{BB}^{\prime}$-spectrum), 7.72 $(4$, nearly s), $8.93(2, \mathrm{~s})$; mass spectrum m/e (\%) 341 (M, 52), 284(10), 274(38), 270(100), 127(9), no other peak larger than $5 \%$.

$\mathrm{C}_{23} \mathrm{H}_{23} \mathrm{~N}_{3}$

Calcd C 80.91 H 6.79 N 12.31,

Found C 80.89 H 6.94 N 12.09.

\section{5-n-Pentyl-2-(4'-cyano-4-biphenylyl)-pyrimidine}

(4, $\mathrm{R}=\mathrm{C}_{5} \mathrm{H}_{11}$, Scheme 4)

$34.5 \mathrm{~g}$ of 4 -bromobiphenyl in $164 \mathrm{ml}$ of methylene chloride are treated at approx. $2^{\circ} \mathrm{C}$ with $60.6 \mathrm{~g}$ of titanium tetrachloride. $20.7 \mathrm{~g}$ of dichloromethyl methyl ether are added dropwise at the same temperature over a period of $40 \mathrm{~min}$. The cooling bath is then removed and the mixture is stirred for $21 \mathrm{~h}$ at room temperature. The mixture is poured on to ice and the product is extracted with ether in the customary manner. Chromatography on silica gel 60 with benzene as the eluting agent initially gives unreacted starting material and then 4'-bromo4-biphenylaldehyde.

From $17.5 \mathrm{~g}$ of $4^{\prime}$-bromo-4-biphenylaldehyde and $4.4 \mathrm{~g}$ of hydroxylamine hydrochloride in $35 \mathrm{ml}$ of methanol and $70 \mathrm{ml}$ of pyridine there is obtained, after boiling under reflux, crude oxime which is converted into the nitrile by heating for $15 \mathrm{~h}$ in acetic anhydride. The mixture is concentrated as much as possible on a rotary evaporator. The residue is poured on to ice and dilute sodium hydroxide solution and the product is isolated with ether in the customary manner.

After treatment with hexane, the $4^{\prime}$-bromo-4cyanobiphenyl melts at approx. $150^{\circ} \mathrm{C}$.

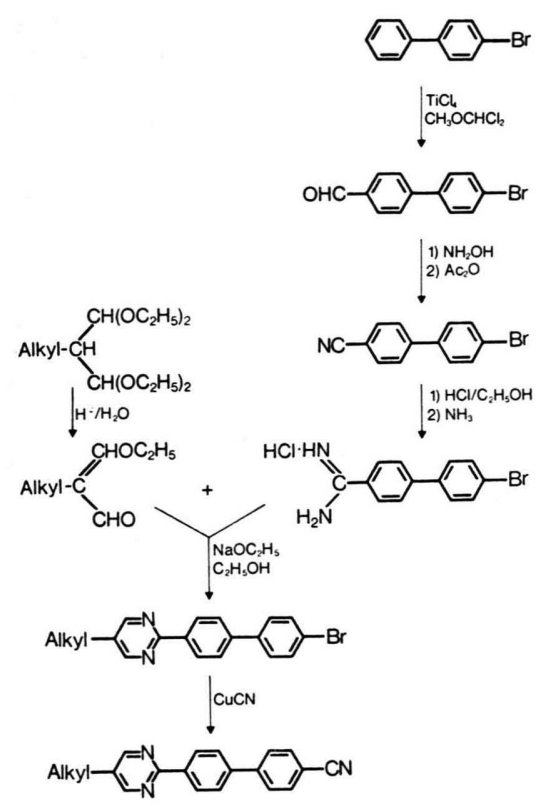

Scheme 4. Synthesis of

5-alkyl-2-(4'-cyano-4-biphenylyl)-pyrimidines.

Dry hydrogen chloride is passed into a mixture of $5.6 \mathrm{~g}$ of $4^{\prime}$-bromo-4-cyanobiphenyl and $1 \mathrm{~g}$ of absolute ethanol in $25 \mathrm{ml}$ of toluene until the mixture becomes saturated. After stirring for 3 days at room temperature, the precipitate is filtered off and washed with toluene. The residue is suspended in $5 \mathrm{ml}$ of absolute ethanol whilst still moist and the suspension is treated with $1.3 \mathrm{~g}$ of ammonia in the form of a $10 \%$ ethanolic solution. After stirring for 3 days at room temperature, the precipitated 4'-bromo-4-biphenylamidine hydrochloride is separated, washed with ether and dried. $5.8 \mathrm{~g}$ of $n$-pentyl-malonic tetraacetal [7] in $10 \mathrm{ml}$ of ethanol are stirred overnight at room temperature with $0.75 \mathrm{ml}$ of water and 1 drop of concentrated sulphuric acid. The mixture is then diluted with ether, extracted with sodium carbonate solution, washed neutral and evaporated.

$1.42 \mathrm{~g}$ of the thus-obtained crude 2-n-pentyl-3ethoxy-acrolein [7] are dissolved in a sodium ethylate solution (obtained from $480 \mathrm{mg}$ of sodium in $40 \mathrm{ml}$ of ethanol) and $2.6 \mathrm{~g}$ of the $4^{\prime}$-bromo4-biphenylamidine hydrochloride are added. The mixture is then stirred for 3 days at room temperature. After some of the solvent has been distilled off, water is added and the mixture is extracted with chloroform in the customary manner. Upon crystallization from ethanol, there is obtained 5 - $n$-pentyl2-(4'-bromo-4-biphenylyl)-pyrimidine in the form of needles of melting point $137^{\circ} \mathrm{C}$ and clearing point $197^{\circ} \mathrm{C}$.

$1.5 \mathrm{~g}$ of 5 - $n$-pentyl-2-(4'-bromo-4-biphenylyl)pyrimidine are heated to reflux for $22 \mathrm{~h}$ with $2.5 \mathrm{~g}$ 
of copper(I) cyanide in $50 \mathrm{ml}$ of dimethylformamide. After cooling, $25 \mathrm{ml}$ of $10 \%$ aqueous ethylenediamine solution are added and, after stirring for a short time, the mixture is shaken again with $25 \mathrm{ml}$ of ethylenediamine solution and then washed until it gives a neutral reaction. The crude concentrate is chromatographed on silica gel 60 with toluene $/ 1 \%$ acetone. Recrystallization of the pure fractions from ethyl acetate yields 5 - $n$-pentyl-2-(4'-cyano4-biphenylyl)-pyrimidine; m.p. $124^{\circ} \mathrm{C}$; clp. $259.5^{\circ} \mathrm{C}$.

NMR $\delta 0.92 \mathrm{ppm}(3$, nearly $\mathrm{t}, J=7 \mathrm{~Hz}), 1.25-1.8$ $(6, \mathrm{~m}), 2.65(2, \mathrm{t}, J=7.5 \mathrm{~Hz}), 7.68,8.51$ (4, centers of $\mathrm{AA}^{\prime} \mathrm{BB}^{\prime}$-spectrum), $7.72(4$, nearly s), $8.64(2, \mathrm{~s})$; mass spectrum $m / e(\%) 327$ (M, 100), 270(92), 243(14), $204(19), 177(5), 39(23)$, no other peak larger than $5 \%$.

\section{$\mathrm{C}_{22} \mathrm{H}_{21} \mathrm{~N}_{3}$ \\ Calcd C 80.70 H $6.46 \quad \mathrm{~N} 12.83$, \\ Found C 80.49 H 6.46 N 12.77 .}

The authors would like to thank Miss D. Keller, Miss Ch. Schenk, Miss S. Zingg, Mr. G. Daub, Mr. J. P. Gaertner, Mr. A. Germann, Mr. R. Mory, Mr. H.-R. Saladin, and Mr. H. Weber, who carried out the experimental chemical work. We are also grateful to Mr. B. Halm and Mr. F. Wild for the measurements of the thermoanalytical data and to Dr. K. Schleich for the discussion of the results. We thank Mr. W. Meister, Dr. W. Vetter, and Dr. W. Arnold for the discussion of the NMR and mass spectra. Microanalyses have been carried out under the supervision of Dr. A. Dirscherl.
[1] H. Zaschke and H. Schubert, J. Prakt. Chem. 315, 1113 (1973).

[2] H. Schubert and H. Zaschke, J. Prakt. Chem. 312, 494 (1970).

[3] G. Kraus, K. Seifert, H. Zaschke, and H. Schubert, Z. Chemie 11, 22 (1971); D. Demus, S. Diele, M. Klapperstück, V. Link, and H. Zaschke, Mol. Cryst. Liq. Cryst. 15, I61 (1971).

[4] H. Zaschke, J. Prakt. Chem. 317, 617 (1975); H. Zaschke and R. Stolle, Z. Chemie 15, 441 (1975); H. Zaschke, Z. Chemie 17, 63 (1977).

[5] A. Boller, M. Cereghetti, M. Schadt, and H. Scherrer, Mol. Cryst. Liq. Cryst. 42, 215 (1977).

[6] A. R. Todd and F. Bergel, J. Chem. Soc. 1937, 364.
[7] E. Breitmaier and S. Gassenmann, Chem. Ber. 104, 665 (1971); R. Kruse and E. Breitmaier, Chem. Ztg. 101, 305 (1977).

[8] G. W. Gray, K. J. Harrison, and J. A. Nash, J. Chern. Soc., Chem. Commun. 1974, 431.

[9] G. W. Gray, J. Phys. (Paris), Colloq. 1975(1), 337; G. W. Gray and A. Mosley, J. Chem. Soc., Perkin Trans. II 1976, 97.

[10] W. E. Parham and L. J. Reed, Org. Syn. Coll. 3, 395 (1955).

[11] S. G. Levine, J. Am. Chem. Soc. 80, 6150 (1958); G. Wittig and M. Schlosser, Chem. Ber. 94, 1373 (1961); G. Wittig, W. Böll, and K.-H. Krück, Chem. Ber. 95, 2514 (1962). 